\title{
A STUDY ON THE PRESENT STATUS AND ISSUES OF ORGANIC PADDY RICE EXPANSION IN NORTHEAST SEMI-ARID REGION OF CHINA: THE CASE STUDY OF T FARM, BAICHENG CITY, JILIN PROVINCE
}

Jian Ma, Alias Abdullah and Hajime Kobayashi

\section{Introduction}

Rice consumption has shifted from quantity to quality due to rapid economic development and a higher standard of living in China. Known for its safe and healthy characteristics, organic rice in China has become increasingly popular among highincome groups who are becoming more concerned about food safety. Due to $60 \%$ of Chinese viewing rice as their staple food, organic paddy rice is being produced more widely in China. By 2005, the production of organic paddy rice had reached about 34,000 ha which produced 130 thousand tons of organic rice. Three provinces have become the most important in organic rice production. Heilongjiang, Jilin and Liaoning provinces account for $60-70 \%$ of all organic rice produced from the northeastern part of China. ${ }^{1}$

Bao (2000), Jin (2007), Chen (2009) and Lin (2010) had previously done research on the production of organic rice. Their studies focused on the status, policy, certification of organic paddy rice development and the profit comparison between conventional and organic rice. However, in depth research of farm management is relatively weak. Moreover, the change in the technology, production cost and profit of organic paddy rice from conversion period to certification has not been researched thoroughly. This paper examines farm management in Baicheng city, in Jilin province. The emphasis is through field surveys which analyzes the change of organic paddy rice production from the conversion period to after certification. Technology, cost and profit analysis will be examined to understand the extent to which conditions are sustainable for large-scale organic paddy rice production.

1 Liandeng Jin, "A Study on the Present Situation and Development and Countermeasures of Organic Rice Production in China," China Rice, Vol. 3-1, 2007, pp. 1-4. (In Chinese) 


\section{Study Area}

Baicheng city is located in the western part of Jilin province, China. Ecologically it transits from semi-humid grassland to semi-arid grassland. With a drought index of 4.49 , an average annual rainfall of $411.4 \mathrm{~mm}$, and annual evaporation of $18461 \mathrm{~mm}$, these characteristics belong to a semi-arid environment. Baicheng city lacks surface water as well as industrial and agricultural production and its urban water supply is dependent on groundwater. ${ }^{2}$ In the past, the city concentrated on wheat production. Eventually, Baicheng city began to improve land salinization and alkalization though paddy farming in 1986 and from 1989 onwards, this was expanded to other areas. Within twenty years and by 2007, paddy farming had produced a total of 611,354 tons of rice.

Located in Linhai town of Taobei distract, Baicheng city, a T farm was set up in 1962. A T farm, is a huge comprehensive enterprise which includes the collection of rice production, rice processing and sales. In 2009, the total land areas was 7,000 ha. There were 133 personnel of whom 50 were management staff, 21 technical staff and 62 staff involved in services. The fixed assets of this T farm were 17.16 million yuan. Figure 1 shows the organizational chart of $\mathrm{T}$ farm. The farm director was responsible for the operational department, which included the management, sales and fixed assets management divisions (FAMD). One secretary was in charge of the grain store. Two deputy directors were appointed to take care of production and administration matters. In the agricultural technology promotion center (ATPC), only one agronomist was responsible for the promotion, popularization and application of agricultural technology within the T farm.

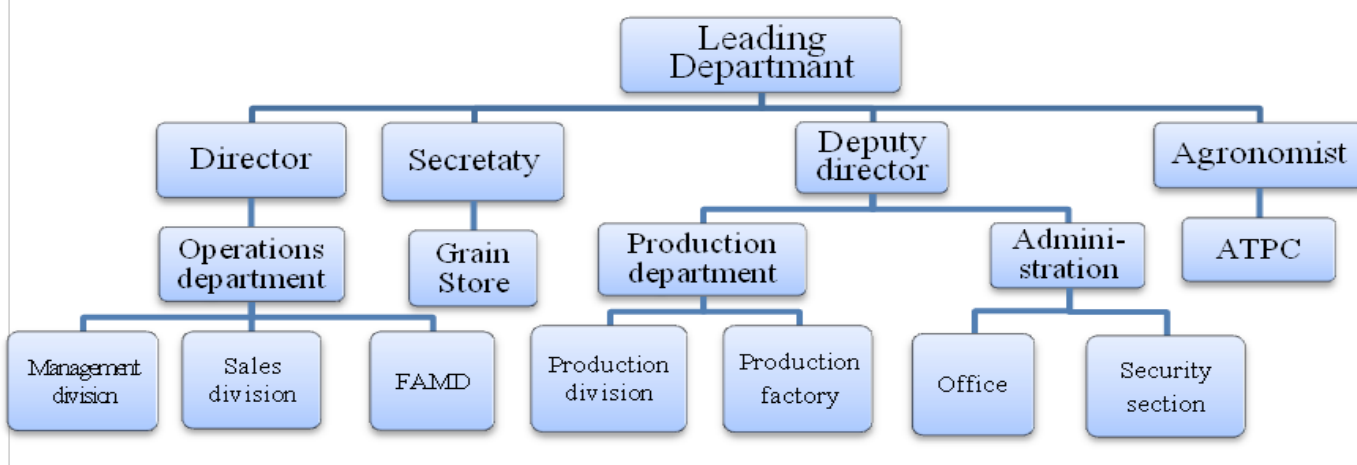

Figure 1: The Organization Chart of $\mathrm{T}$ farm

\section{Data}

Data was collected twice from field surveys. The first field survey was conducted in September 2007, which was during the conversion period of the organic rice farming. Surveys were done by visiting two organic paddy rice farmers named A and B. For the purpose of comparison, we chose another two conventional rice farmers named $\mathrm{C}$

2 Wanbin Shen, Zhiwei Mao, Hua Su, Guozhang Bao, "Planning for the Rational Exploitation and Utilization of Groundwater Resources in Baicheng City," Arid Zone Research, Vol. 21-3, 2004, pp.215-219. (In Chinese) 
and D. The second field survey was conduct in April 2009, when the T farm obtained certification in organic rice production. We used the survey lists when visiting the two organic paddy rice farmers $\mathrm{A}$ and $\mathrm{B}$ again to understand the production information in the certification time, which is essential to compare with the conversion period.

\section{Paddy Farming In T Farm}

\section{Background of paddy farming development}

Table 1 Rice production in T Farm

\begin{tabular}{|c|c|c|c|c|c|c|c|}
\hline & & & 2005 & 2006 & 2007 & 2008 & 2009 \\
\hline \multirow{4}{*}{ Organic rice } & \multirow{2}{*}{ Conversion } & Area & 6.5 & 15.5 & 36.5 & - & - \\
\hline & & Farmer & 1 & 2 & 2 & - & - \\
\hline & \multirow{2}{*}{ Certification } & Area & - & - & - & 100 & 653 \\
\hline & & Farmer & - & - & - & 24 & 102 \\
\hline \multirow{2}{*}{\multicolumn{2}{|c|}{ Conventional rice }} & Area & 5293.5 & 5284.5 & 5263.5 & 5,200 & 5,000 \\
\hline & & Farmer & 719 & 718 & 718 & - & - \\
\hline
\end{tabular}

Source: Field surveys conducted in 2007 and 2009

The $\mathrm{T}$ farm began in 1990 within the context of paddy farming development in Baicheng city. Before 1990s, local farmers of Baicheng city were primarily growing corn and beans, and they had no experience growing rice. In 1992, there were efforts and advertisements to assemble a group of farmers with experience from the central and eastern regions of Jilin province. Paddy farmers increased from 50 in 1992 to 720 in 2009. $20 \%$ of them were local farmers and the rest of the $80 \%$ farmers came from other regions.

By 2005, the T farm became a pioneer in organic paddy rice production in Baicheng city. In 2006 which was the starting of the conversion period, two farmers cultivated organic paddy rice covering 15.5 ha. By 2009 , which was the certification period, a total of 102 farmers had cultivated 653 ha. In the same period, the areas of conventional paddy rice in the T farm area decreased to 5,000 ha in 2009 when compared to 5,284.5 ha in 2006.

Conditions for organic paddy rice development in the $T$ farm

1) The landscape

The location of the $\mathrm{T}$ farm in the semi-arid region made a huge difference in organic paddy farming. An average annual sunshine of 2919.4 hours and frost-free period of 157 days together with positive sunlight conditions met the basic requirement for rice growth. Where irrigation is concerned, a total quantity of water resource was 2.27 billion cubic meters existed in the area of investigation. Among others, this included 2.08 billion cubic meters of groundwater, surface water resources of 189 million cubic meters, and 
available groundwater resource of 1.54 billion cubic meters and the existence of annual transiting rivers water supply of 22 billion cubic meters.

\section{2) Technical conditions}

20 years of paddy farming in the $\mathrm{T}$ farm saw the accumulation of rich experiences on paddy rice cultivation. Not surprisingly, one very well paid agricultural expert who was an agronomist was appointed to set up an agricultural technology promotion center (ATPC) designed to solicit technical talents. At present, there are 10 agronomy graduates from the Jilin Agricultural University, both with undergraduate and graduate degrees who work as technicians at the ATPC. The increasing number of technical talents is being ensured to provide more solid technical support for organic paddy rice production in the $\mathrm{T}$ farm.

\section{Organic Paddy Rice Development in the T Farm}

\section{Basic position of surveyed farmers}

A is the first farmer to cultivate organic paddy rice in the $T$ farm. He was born in Shulan city, which is a traditional paddy farming area in the middle of Jilin province. Farmer A started his paddy planting since he was 25 years old. Since the per capita farming area was only 10 ha in his hometown, which was not enough for daily subsistence, he decided to join the $\mathrm{T}$ farm in 1992 through an introduction from a friend who was already farming there. Table 2 shows that farmer $\mathrm{A}$ has 4 occupants in his family. His wife was the main worker in an area of area of 6.25 ha in 2006. For organic paddy rice production, an employer usually has 25 temporary workers with one long-term worker. Since farmer A is located in the groundwater irrigation area, his cultivation area consisted of one medium tractor with one combine-harvester, two pumps and electrical-machines for drawing groundwater.

Farmer $B$ is the second organic paddy rice farmer who has been involved in the farm since 2005 before having focused on conventional paddy rice cultivation. He was born in Huinan county, a traditional rice farming area in the south of Jilin province. His father had long term experience with rice planting. Due to the father's influence, farmer B started his own rice planting from the age of 23 years old and came to T farm in 1995 with an introduction from his countryman. Table 2 shows that his organic paddy rice area was 9.2 ha in 2006 where he employed 37 individuals as temporary labourer and one person as a long-term worker. In addition he had two tractors and an electrical machine due to the cultivation area of farmer B which is located in the reservoir water irrigation region.

Farmer $\mathrm{C}$ is the youngest one of four surveyed farmers, but with a history of rice farming of 15 years. He was born in the Yanbian Korean prefecture, which is the earliest paddy rice growing area in Jilin province. However, the rice area per capita is only 30ha, which is inadequate for family life. Therefore, he came to T farm in 1996 after seeing the advertisement soliciting for farmers who had long term experience in paddy rice planting. In 2006 farmer $C$ contracted 18 ha for conventional paddy rice 
under through irrigation by groundwater, and he employed 45 temporary workers and two long-term labourers.

After losing his job, $\mathrm{D}$ became the local farmer, to have started rice planting in $\mathrm{T}$ farm from 2001. He contracted 22 ha conventional paddy rice areas in 2006, and rice planting made him wealthy. He managed to employ 50 temporary workers and three long-terms labourers. Besides rice planting, farmer D also has one restaurant and one store that supplies agricultural materials.

Table 2 Farmers situation

\begin{tabular}{|c|c|c|c|c|c|c|}
\hline \multirow[b]{2}{*}{ Year } & \multicolumn{2}{|c|}{$\mathrm{A}$} & \multicolumn{2}{|r|}{ B } & C & \multirow[t]{2}{*}{$\mathrm{D}$} \\
\hline & 2006 & 2008 & 2006 & 2008 & 2006 & \\
\hline $\begin{array}{l}\text { Rice area (ha) } \\
\text { organic } \\
\text { conventional }\end{array}$ & 6.25 & 10.8 & 9.2 & 7.65 & 18 & 22 \\
\hline Machinery & & & & & & \\
\hline $\begin{array}{l}\text { Seeder } \\
\text { tractor* } \\
\text { combine-harvester } \\
\text { pump } \\
\text { electrical-machine }\end{array}$ & $\begin{array}{l}1(\mathrm{M}) \\
1 \\
2 \\
2 \\
\end{array}$ & $\begin{array}{l}1(\mathrm{M}) \\
1(\mathrm{M}) \\
4 \\
4\end{array}$ & $2 \mathrm{~S}, \mathrm{~L}$ & $\begin{array}{l}2 \mathrm{~S}, \mathrm{~L} \\
2\end{array}$ & $1(\mathrm{~L})$ & $\begin{array}{l}2 S, L \\
1 \\
5 \\
5 \\
\end{array}$ \\
\hline
\end{tabular}

Note: S , M and L is the size of machinery used.

Data source: Field surveys conducted in 2007 and 2009.

\section{Conversion period of organic paddy rice}

Conversion period means the period from the beginning of cultivation management in compliance with the standards of organic production until the date when its products have been certified as organic. The conversion period should be last at least 24 months in the case of annual crops, and at least 36 months for perennial crops. The history of conventional paddy rice production in $\mathrm{T}$ farm has continued for 15 years from 1992 to 2007. Hence, the conversion period of organic paddy rice should be at least 36 months, and 2006 is the second year of the conversion period.

\section{1) Comparison of technology during conversion period}

In the conversion period, there are some technological standards and measurements for organic paddy rice production. First, this sort of farming prohibits the utilization of chemical fertilizers and pesticides. Second, it advocates the prevention of disease, pest and weed infestation by biological methods or the use of the bio-pesticides. Third, it advocates a balanced proportion of fertilizer utilization.

Table 3 shows that there are some differences in fertilization, pest control and weeding as well as in the aspects of work period, labor and input quantity. First, in terms fertilization, farmers A and B used organic fertilizer three times and farmers C and D used chemical fertilizer five and four times respectively. Labour use in fertilization of A and B depended on both family labour and temporary hire labour as well as long-term labour. But farmers $C$ and D just depended on temporary workers due to large paddy rice areas. Total quantity of fertilizers used shows farmers A and B used $63 \mathrm{~kg}$ and 45 
$\mathrm{kg}$ respectively, farmers $C$ and D used $47.3 \mathrm{~kg}$ and $42.1 \mathrm{~kg}$ for per-10a respectively. In spite of the fertilizer input of farmers $A$ and $B$ being higher than $C$ and $D$, the structure of $\mathrm{N}, \mathrm{P}, \mathrm{K}$ is more balanced. However, the per-10a nitrogen input differs as farmers $\mathrm{A}$ and B just used $21 \mathrm{~kg}$ and $15 \mathrm{~kg}$ respectively. In contrast, farmer C and D used $28.3 \mathrm{~kg}$ and $24.8 \mathrm{~kg}$ respectively.

Table 3 Technology comparison on fertilization, pest control and weeding (2006)

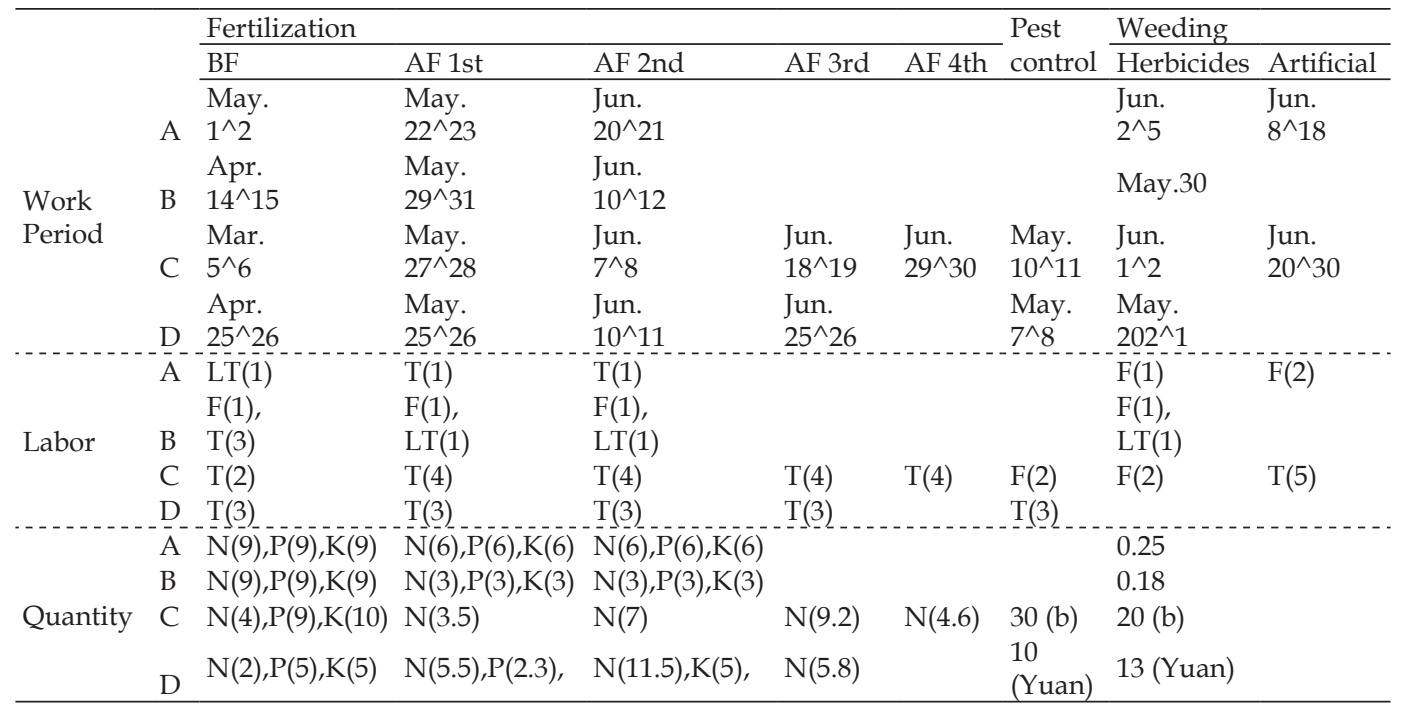

Note: 1) BF means base fertilizer, $\mathrm{AF}$ is additional fertilizer, $\mathrm{F}$ is family, $\mathrm{T}$ is temporary hire and LT is long-term 2) Percentage of N, P and $K$ of organic fertilizer is $15 \%$ for each hundred kilograms. Percentage of N, P and $\mathrm{K}$ of chemical fertilizer is that such as Carbamide [CO(NH2)2], which includes N. for $46 \%$. Diammonium [NH4H2PO4], which includes P for $46 \%$ and $\mathrm{N}$ for $18 \%$. Lemery [K2O], which. includes $\mathrm{K}$ for $50 \%$ for each hundred kilograms.

Farmer $\mathrm{A}$ and $\mathrm{B}$ did not use any pesticides for pest control because the agronomist of $\mathrm{T}$ farm informed them that there is little chance pests and diseases due to the dry weather condition. On the other hand, farmer $C$ used 30 bottles chemical insecticides for total 18 ha, and farmer D also used agrochemicals which costs 10 yuan per-10a. For weeding, farmer A used both bio-herbicides and hand weeding methods, the labour consisted mainly of family. Farmer B just used bio-herbicides as $0.18 \mathrm{~kg}$ input for per10a. Farmer $\mathrm{C}$ used both 20 bottles chemical herbicides and hand weeding for a total of 18 ha, and farmer D used chemical herbicides which costs 13 yuan per-10a.

The use of organic fertilizer and bio-pesticides instead of chemical fertilizers and chemical pesticides is not enough as more complex technology is required for organic paddy rice production compared to conventional paddy rice production. But it is a good step to use organic fertilizers and bio-pesticides, as it is better than chemical fertilizers and pesticides for both environment protection and rice quality. Yet, developing the technology to address organic paddy rice production is a very important subject that $\mathrm{T}$ farm needs to solve in the future. 
2) Analysis of cost of rice production and profitability

Table 4 shows the differences between four farmers in terms of cost of rice production and profitability of four farmers, variable cost and fixed cost. In terms of variable cost, fertilizer is a major cost but the cost for farmers $C$ and D is higher than farmers $A$ and $\mathrm{B}$ due to the repeated input and high prices of chemical fertilizers whereby the price of per-kg organic fertilizer is only 1.5 yuan compared to the price of nitrogen and potash fertilizers which is 2.8 yuan for the same unit.

Another important input in variable cost was the fuel costs, which includes the cost of electricity and diesel. Farmers A, C and D had higher expenditures than farmer $\mathrm{B}$, since $\mathrm{B}$ only used diesel due to irrigation supplied by the dam without any electrical power inputs. In contrast, farmers A, C, and D had to use groundwater for irrigation that uses electrical power.

The third important input of variable costs is the hiring of labour, which includes temporary and long- term workers. But the cost of hiring temporary workers is higher than long-term workers as more hired workers are needed as paddy rice production is a more complex process than any other crops. Furthermore, temporary hired workers play a very important role not only in organic paddy rice production but also in conventional paddy rice production. However, as the economy develops rapidly in cities in China, younger people from the countryside prefer to move to these cities. Also as aged people increase in China, the hiring price of temporary workers will eventually rise due to lack of surplus workers, compared to the past. Therefore, the it is important to find a solution to the potential shortage of temporary hired workers in future paddy rice production.

In terms of fixed costs, the land cost increased to 380 yuan per-10a in 2006 to 340 and 360 yuan for per-10a in 2004 and 2005respectively. Studies have shown thatt land cost will continue to increase as farm land becomes scarce due to lack of resources in China.

Consequently, some organic paddy rice production during the conversion period did not receive the organic certification. Therefore, the product was sold in accordance with the price of conventional rice, due to lower yields than conventional rice farming. For example, the net profit of farmers $\mathrm{A}$ and $\mathrm{B}$ during the conversion period was much lower than farmers $\mathrm{C}$ and $\mathrm{D}$. As a farmer, pursuing maximization is the basic goal of agricultural production. However, lower profits compared to conventional paddy rice goes against this basic principle. Therefore, in order to protect the farmers' profits and simultaneously develop organic paddy rice production, the T farm signed a contract with farmers A and B. The contract ensured organic farmers A and B that the farm will ensure their income for a yield of $11,000 \mathrm{~kg}$ per-ha no matter how much the farmers produced. But this purchase price is the same as conventional paddy rice. Therefore, the contract income for per-10a of farmers A and B was 2,046 yuan respectively. The net profit for farmer A was 810 yuan, farmer B was 915 yuan, which was higher than farmers $C$ and D`s income which was 465 yuan and 651 yuan respectively.

\section{Organic paddy rice production after organic certification}

$\mathrm{T}$ farm received the organic certification for organic rice production from the Beijing Land Bridge Quality Inspection Certification Center (BQC) starting from 2008. In order to facilitate centralized management of organic rice production, under the unified 
Table 4: Cost of rice production and profitability for Per-10a of four farmers (2006) Unit: Yuan, Yuan/kg, Yuan/10a

\begin{tabular}{|c|c|c|c|c|c|}
\hline \multirow{2}{*}{\multicolumn{2}{|c|}{ Variable cost (V) }} & $\mathrm{A}$ & $\mathrm{B}$ & $\mathrm{C}$ & $\mathrm{D}$ \\
\hline & & 678 & 592 & 666 & 773 \\
\hline Seed & & 27 & 12 & 20 & 20 \\
\hline \multirow{2}{*}{ Fertilizer } & Manures & 109 & 158 & 1 & - \\
\hline & Chemical & - & - & 218 & 264 \\
\hline Pesticides & & 14 & 12 & 5 & 30 \\
\hline Fuel & & 153 & 72 & 103 & 177 \\
\hline Tools & & 22 & 21 & 19 & 24 \\
\hline Repair & & 64 & 11 & - & 15 \\
\hline \multirow{2}{*}{ Hired labor } & Temporary & 161 & 234 & 216 & 134 \\
\hline & Long-term & 128 & 72 & 84 & 109 \\
\hline Fixed cost $(F)$ & & 558 & 539 & 405 & 463 \\
\hline Depreciation of fixed-assets & & 149 & 35 & 14 & 60 \\
\hline Drainage and Irrigation & & - & 105 & - & - \\
\hline Family labor & & 13 & 7 & 2 & 2 \\
\hline land cost & & 380 & 380 & 380 & 380 \\
\hline Miscellaneous & & 16 & 12 & 9 & 21 \\
\hline Total cost $(\mathrm{TC})=\mathrm{V}+\mathrm{F}$ & & 1,236 & 1,131 & 1,071 & 1,236 \\
\hline Yield of rough rice $(\mathrm{Y})$ & & 850 & 750 & 950 & 1000 \\
\hline Sale price* (SP) & & 1.86 & 1.86 & 1.86 & 1.86 \\
\hline Total income $(\mathrm{TL})=\mathrm{SP} * \mathrm{Y}$ & & 1581 & 1395 & 1767 & 1860 \\
\hline Marginal profit (MP) & & 903 & 803 & 1101 & 1087 \\
\hline Breakeven point (BEP) & & 977 & 936 & 650 & 792 \\
\hline Net profit $(\mathrm{NP})=\mathrm{TL}-\mathrm{TC}$ & & 345 & 264 & 696 & 624 \\
\hline
\end{tabular}

Data source: Field Survey in 2007

planning, the $\mathrm{T}$ farm limited the cultivation area only to groundwater irrigation areas. Therefore, the situation of farmers A and B also changed. In the case of farmer A the size of the organic paddy rice areas increased from 6.25 to 10.8 ha because farmer $\mathrm{A}$ uses groundwater irrigation. On another hand, farmer B changed from organic to conventional paddy rice production which changed his size of the cultivation area from 9.2ha to 7.65 ha.

\section{1) Comparison of technology after certification}

Similar to the analysis during the conversion period, we have to analyze the change of paddy rice technology in fertilization, pest control and weeding. Firstly, farmer A used organic fertilizers three times, but the difference is in the labour input where he mainly used members of his family and long-term labourers, not depending on temporary hired workers compared to during the conversion period. For quantity, the N, P and $\mathrm{K}$ input of farmer $\mathrm{A}$ was 19,8 and $8 \mathrm{~kg}$ for per-10a with the rate of 2.4:1:1. On the other hand, farmer B used chemical fertilizers four times, the labour input also depended on family labour, the quantity input of N, P and K was 60, 6 and $6 \mathrm{~kg}$ for per-10a, with the rate of 10:1:1. The P and K input was less than farmer $A$, but the $\mathrm{N}$ input was three times more and the total input was more than double. In other words, the fertilization structure of farmer A was more rational than farmer B due to farmer B`s over emphasis on nitrogen inputs. 
Table 5: The change of production technology after certification on fertilization, pest control and weeding

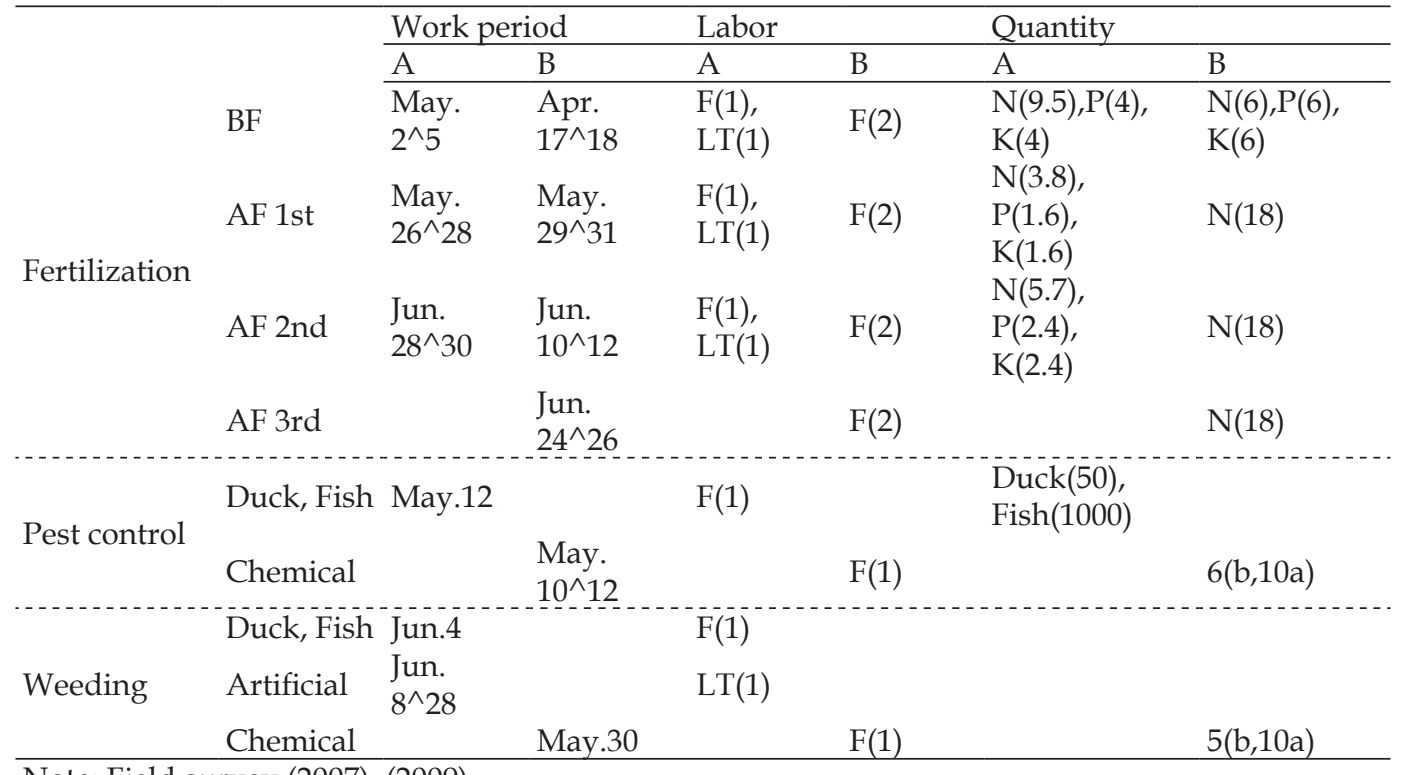

Note: Field survey (2007), (2009).

In pest control and weeding, the difference compared to the conversion period was that farmer A used rice duck-farming and fishing-farming technologies in certification. The utilization quantity of ducks used was 50 with 1000 fishes. It shows that the $T$ farm followed in full the technological measures of organic product production without any inputs of chemical fertilizers and pesticides.

2) Comparison of labour hours

Table 6: Comparison of labor time and percentage for per 10a

\begin{tabular}{|c|c|c|c|c|c|c|c|c|c|c|c|c|c|c|c|c|}
\hline & \multicolumn{8}{|l|}{$\mathrm{A}$} & \multicolumn{8}{|l|}{ B } \\
\hline & \multicolumn{4}{|c|}{ Conversion } & \multicolumn{4}{|c|}{ Certification } & \multicolumn{4}{|c|}{ Conversion } & \multicolumn{4}{|c|}{ Conventional } \\
\hline & \multirow{2}{*}{ Time } & \multicolumn{3}{|c|}{ Percentage (\%) } & \multirow{2}{*}{ - Time } & \multicolumn{3}{|c|}{ Percentage (\%) } & \multirow{2}{*}{ - Time } & \multicolumn{3}{|c|}{ Percentage (\%) } & \multirow{2}{*}{ - Time } & \multicolumn{3}{|c|}{ Percentage (\%) } \\
\hline & & $\mathrm{F}$ & $\mathrm{T}$ & LT & & $\mathrm{F}$ & $\mathrm{T}$ & LT & & $\mathrm{F}$ & $\mathrm{T}$ & LT & & $\mathrm{F}$ & $\mathrm{T}$ & LT \\
\hline Seeding & 5.3 & 55 & 30 & 15 & 2.6 & 50 & & 50 & 7.0 & 37 & 34 & 29 & 3.2 & 50 & & 50 \\
\hline Plowing & 1.5 & 47 & 53 & & 0.4 & 100 & & & 1.1 & 27 & 73 & & 0.4 & 100 & & \\
\hline Pudding & 0.2 & 100 & & & 0.6 & 100 & & & 0.4 & 100 & & & 0.7 & 100 & & \\
\hline Fertilization & 0.5 & 40 & & 60 & 1.2 & 50 & & 50 & 1.1 & 46 & 18 & 36 & 2.0 & 50 & & 50 \\
\hline Transplanting & 20.4 & 6 & 94 & & 13.3 & & 100 & & 11.4 & & 100 & & 10.8 & & 100 & \\
\hline Hand weeding & 1.9 & 100 & & & 3.6 & 50 & & 50 & 1.3 & & 100 & & & & & \\
\hline Management & 9.6 & & & 100 & 5.6 & & & 100 & 6.7 & & & 100 & 7.8 & & & 100 \\
\hline Harvesting & 2.4 & 21 & 79 & & & & & & 0.4 & 100 & & & 0.4 & & 100 & \\
\hline Total & 41.8 & 46 & 32 & 22 & 27.3 & 50 & 14 & 36 & 29.4 & 38 & 41 & 21 & 25.3 & 42 & 29 & 29 \\
\hline
\end{tabular}

Compared with the conversion period, for either farmer A or B, their per-10a paddy working hours were reduced. Firstly, per-10a paddy labour time of farmer A 
during the conversion period was 41.8 hours, while after certification only 27.3 hours, shortened by nearly $35 \%$. Among the reasons, seeding time halved as a small planter machine input, and per-10a rice transplanting time had reduced by 7.1 hours, but compared to the conversion period, the number of temporary hired labourers had not increased. Only large areas led to unit time decreased. Human weeding time increased as the organic paddy rice areas increased, and farmer A had no labour input during harvest due to aid from the $\mathrm{T}$ farms. Then, in the analysis of proportion of labour input, compared with the conversion period, the family labour input proportion of farmer A increased 4\% during certification, but the temporary hired labour proportion declined to $18 \%$, and proportion of long-term hired labourers increased to $14 \%$. In the conversion period, temporary hired workers were not only used in rice planting, but also in seeding, plowing and harvesting, but after certification they were only used in the rice transplanting process.

In the case of farmer $B$, per-10a paddy labor time in the conversion period was 29.4 hours, after certification was 25.3 hours, shortened nearly to $14 \%$. Among the reasons, seeding time was shortened to 3.8 hours due to the decrease in cultivation areas, plowing time also decreased by 0.7 hours. But the labour time for fertilization increased due to the input time and quantity. In the proportion of labour input, compared with the organic rice production in the conversion period, the proportion of family labour input also increased $4 \%$, same as farmer $\mathrm{A}$, but the proportion of temporary hired workers declined $12 \%$, while the proportion of long-term labourers increased to $8 \%$.

3) Analysis of rice production cost and profitability

Table 7 shows the cost and profit comparison between conversion and certification of farmer A, and the organic and conventional paddy rice of farmer B. First of all, the per-10a production cost of farmer A was 1,253 yuan in certification, which is 17 yuan higher than the conversion period. The per-10a variable cost increased to 71 yuan and the fixed cost decreased to 54 yuan.

The variable cost of farmer A shows that the organic fertilizer cost in certification 66 yuan higher than the conversion period due to the price of per-kg fertilizer that reached 2.45 yuan in 2008, an increase to $63.3 \%$ compared to 2006 . Therefore, in order to reduce production cost to keep the enthusiasm of organic farmer, $\mathrm{T}$ farm subsidizes each organic farmer like farmer A 0.7 yuan for per-kg. Therefore, the actual per-kg fertilizer cost farmer A only 1.75 yuan. Another significant increase in variable cost is the temporary hire labour cost, compared with the conversion period; an increase of 123 yuan for per-10a due to the reduction of hired labour .

In terms of fixed cost, due to the organic rice harvest duty in $\mathrm{T}$ farm during certification, farmer A sold his combine-harvester which made the depreciation of fixed assets cost decrease greatly. On the other hand, due to large areas of cultivation and the shortage of temporary hired workers made the hours of family labour increase for harrowing, fertilization and hand weeding.

In the profit analysis of farmer A during certification, the market price of organic rice was 2.2 yuan per-kg, but the per-10a yielded only $700 \mathrm{~kg}$, the per-10a income was 1540 yuan, net profit was 287, which was less 58 yuan than during the conversion period. The reality of low income is contrary to the principle of farmer pursues their profit maximization. Therefore, $\mathrm{T}$ farm has taken the same approach as with the conversion 
period where contract with farmers were signed. The main contents of the contract indicates that regardless of the actual per-10a yield, $\mathrm{T}$ farm will purchase organic paddy rice following the market price of conventional rice in the current year $\times 11,000$ $\mathrm{kg}$ for per-ha yield. For example, in 2008, as the per-10a contract income of farmer A was $1.88^{*} 1,100=2,068$ yuan, which 528 yuan higher than the actual income, while net profit also increased from 287 to 815 yuan.

Table 7: Cost of rice production and profitability for Per-10a of two farmers between 2006 and 2008

\begin{tabular}{|c|c|c|c|c|c|}
\hline & & \multicolumn{4}{|c|}{ Unit: Yuan, kg/10a, Yuan/kg } \\
\hline \multirow[b]{3}{*}{ Variable cost $(\mathrm{V})$} & & \multicolumn{2}{|c|}{ A } & \multicolumn{2}{|c|}{$\mathrm{B}$} \\
\hline & & $\mathrm{C} 1$ & $\mathrm{C} 2$ & $\mathrm{C} 1$ & C3 \\
\hline & & 678 & 749 & 592 & 855 \\
\hline Seed & & 27 & 23 & 12 & 25 \\
\hline \multirow{2}{*}{ Fertilizer } & Manures & 109 & 175 & 158 & - \\
\hline & Chemical & - & - & - & 366 \\
\hline Pesticides & & 14 & - & 12 & 31 \\
\hline Fuel & & 153 & 168 & 72 & 35 \\
\hline Tools & & 22 & 16 & 21 & 17 \\
\hline Repair & & 64 & - & 11 & - \\
\hline \multirow{2}{*}{ Hired labor } & Temporary & 161 & 284 & 234 & 263 \\
\hline & Long-time & 128 & 83 & 72 & 118 \\
\hline Fixed cost $(\mathrm{F})$ & & 558 & 504 & 539 & 599 \\
\hline Depreciation of fixed-assets & & 149 & 32 & 35 & 34 \\
\hline Drainage and Irrigation & & - & - & 105 & 120 \\
\hline Family labor & & 13 & 50 & 7 & 38 \\
\hline land cost & & 380 & 400 & 380 & 400 \\
\hline Miscellaneous & & 16 & 22 & 12 & 7 \\
\hline Total $\cos \bar{t}(\overline{\mathrm{T}} \overline{\mathrm{C}})=\overline{\mathrm{V}}+\overline{\mathrm{F}}-$ & & 1,236 & 1,253 & 1,131 & 1,454 \\
\hline Yield of rough rice $(\mathrm{Y})$ & & 850 & 700 & 750 & 950 \\
\hline Sale price* (SP) & & 1.86 & 2.20 & 1.86 & 1.88 \\
\hline Total income $(\mathrm{TL})=\mathrm{SP} * \mathrm{Y}$ & & 1,581 & 1,540 & 1,395 & 1,786 \\
\hline Marginal profit (MP) & & 903 & 791 & 803 & 931 \\
\hline Breakeven point (BEP) & & 977 & 981 & 936 & 1,149 \\
\hline Net profit $(\mathrm{NP})=\mathrm{TL}-\mathrm{TC}$ & & 345 & 287 & 264 & 332 \\
\hline
\end{tabular}

Note: 1) C1 means conversion, C2 means certification, C3 means conventional.

2) Field survey (2007), (2009).

In the case of farmer B the per-10a production cost of conventional paddy rice was 323 yuan higher than organic paddy rice during the conversion period due to increase of variable costs. Some of the factors include the cost of the chemical fertilizer which was 366 yuan, twice that of the cost of the organic fertilizer. In terms of fixed cost, compared with 2006, the cost of irrigation, family labour and land went up, but per-10a yield of conventional rice was $950 \mathrm{~kg}$, which was $200 \mathrm{~kg}$ higher than organic paddy rice cultivation during the conversion period. Although, as the situation of production cost increased, per-10a net profit of conventional paddy rice for farmer B was still 68 yuan higher than organic rice in conversion period. 


\section{Issues Pertaining to the Sustainable Development of Organic Rice Farming in $\mathrm{T}$ farms}

More than $60 \%$ of Chinese eat rice as staple. More and more are choosing healthy organic rice, especially among the high-income group. As per capita incomes rises, domestic market demand for organic rice will grow and thus China's organic rice market has enormous future potential. Therefore, $\mathrm{T}$ farm aim wants to tap the potential opportunities of organic rice, and thus started to develop organic rice production from 2005. Just after just five years, the organic rice product "Ji Yuan" brand, cultivate in a T farm has become popular in Beijing, Shanghai, and Guangzhou. "Ji Yuan" trademark is also famous in the Jilin Province. Moreover in 2008 "Ji Yuan" organic rice was declared a good brand in the Seventh Changchun Agricultural Product Exhibition. However, though organic rice cultivation has recognition, it faces the following challenges during the production phase and then there are certain factors that will affect the sustainable development of organic rice in $\mathrm{T}$ farms.

\section{The issue of irrigation water resources}

T farm was able to develop large-scale paddy rice due to the existence of groundwater resources, but this resource is limited. Between 1999 and 2009, there has been low rainfall and continuous drought in Baicheng city, which resulted in limited water supply. Simultaneously, the average evaporation (above $1800 \mathrm{~mm}$ ) of groundwater level in Baicheng city is declining annually. From the survey conducted in 2009, data shows that the groundwater levels have dropped at least 5 meters, and in some areas, even to 10 meters in Baicheng city. Therefore, decrease of water resource is one of the most important factors that will restrict the future development of paddy rice farming in $\mathrm{T}$ farms.

\section{The issue of blind expansion of organic rice area which leads to high cost of farm management}

Organic paddy rice areas have grown from 6.5 to 653 ha in T farms, which shows an increase of nearly 100 times during a short period of five years. However, Table 4 and Table 7 shows that per-10a organic rice net profit is lower than conventional rice due to low yields and market prices. Therefore, in order to maintain the enthusiasm of farmers, $\mathrm{T}$ farm had no choice but to give contracts to farmers to buy their crops in order to ensure profits fom organic paddy rice production continued.

For example, in 2008, organic paddy rice areas were 100 hectares. The market price of conventional rice was 1.88 yuan per- $\mathrm{kg}$, according to the formula of sale price of conventional rice $\times$ contract yield $\times$ areas. The T farm paid $1.88 * 11,000 * 100=2,068,000$ Yuan to all organic paddy rice farmers. But the actual per-ha yield of organic paddy rice was just about $7,000 \mathrm{~kg}$, milled organic rice for $50 \%$ were 350 tons. The total sale of organic rice for T farm in 2008 was 335 tons and the total revenue was 2.35 million yuan. The gross profit was 282,000 yuan and the profit rate was only $12.0 \%$. In reality, if one includes the subsidy of organic fertilizer and processing cost of organic rice, the net profit of organic rice will be less than 282,000 yuan. 
Low profits of organic rice is not only contrary to the first objective of profit maximization but it is also against basic management principles as companies want to maximize their profits and reduce cost in order to increase income. For a $\mathrm{T}$ farm, one possible useful method of cost control is by reducing the contract spending, singed with organic paddy rice farmers. But this will result in profit loss which will discourage farmers from growing organic paddy rice, thus affect the sustainable development of organic rice in T farms. This is also a serious issue. During China's agricultural industrialization process, enterprises and farmers pursued profit through the Enterprise+Farmer model. However, the company is always in a stronger position and farmers are always in a weaker position. As such if the T farm doesn' $t$ do well, and it reduces the contract yield, farmers either passively accept or give up planting altogether as land ownership and management rights belong to $\mathrm{T}$ farm and the farmers only obtain utilization rights by paying rent for the land annually. Therefore, the question is how to how ensure the farmers profit while increasing the organic rice profits for $\mathrm{T}$ farms is an important issue to be looked into.

\section{The issue of high production cost of organic paddy rice and the impact of labour shortage}

Throughout the analysis of Tables 4 and 7, profit rates of organic paddy rice during the conversion and certification period for farmer A was only $21.8 \%$ and $18.6 \%$ respectively. The main reason for such a low income is because of the high cost of organic paddy rice production. Therefore, reduction of production costs is very important to improve the management of T farms. Production costs are related to high proportion followed by land rent, hired workers, fertilizers and fuel cost. For example per-ha land rent costs 3,800 yuan in 2006 but in 2008 it rose 200 yuan to 4,000 yuan per-ha. As such, in the long term, rentals will increase parallel to the rise in land prices in China. At the same time, fuel cost, which includes cost of electricity and diesel will rise according increasing energy prices. Therefore, reducing the use of fertilizers and hired labour cost has been an important way for farmer A to manage cost. In terms of hired labour cost, limited family labour and the large areas of organic paddy rice farming made it necessary to maintain long-term labourers, and temporary hired labourers. As such, mechanizing rice transplanting is an effective way to overcome labor shortage. Not only the farmers but $\mathrm{T}$ farm management also must face and resolve organic rice technical issues for future production.

The issue of expanding sales channels, actively participating in competitive markets and expansion of consumer groups and the development of an organic rice market

The T farm sold 3.35 million tons of organic rice in 2008. 50,000 tons of rice was sold in local markets 10 yuan per-kg. 800,000 tons of rice was sold in outside markets through phone and internet communication, and the other 2.5 million tons of rice was sold to company staff and supervisors for 6 yuan per-kg. Local sales only contributed to $1.5 \%$ of total sales due to the expensive pricing compared to the price of local conventional rice which was only 3.0 yuan per-kg, which was less than $1 / 3$ of the organic rice sales price. The main form of local sale is through agents who sell to stores. The $\mathrm{T}$ farm management sold to the agent 10 yuan per-kg of rice and then the same rice was sold by the agent in shops for 20 yuan for per-kg. Unfortunately few consumers bought the 
rice due to its high pricing. Finally 50,000 tons of rice was mainly bought by staff of local government and by private consumers at a very low rate. The rest of 800,000 tons was sold to outside markets in big cities like Beijing, Shanghai, Guangzhou but in these cities the selling of organic rice faces intense competition. Therefore, selling 800,000 tons of organic rice is not easy for $\mathrm{T}$ farms in big cities with a 5 year history of organic rice production. The expensive pricing of organic rice is the main reason for difficulty in selling in local markets. The competitive pricing is another factor that $\mathrm{T}$ farm have to face. The issue is how to sell under intense competition and simultaneously expand organic rice production. Therefore, by adjusting prices, developing local demand for organic rice, expanding sale channels inside and outside the province should be some of the measures taken to sustain organic rice development in $\mathrm{T}$ farms.

\section{Conclusion}

By attracting farmers who had previous experience in planting rice conventionally and by strengthening the technology input, the $\mathrm{T}$ farm has come a long way in terms of expansion of cultivation areas within a period of 10 years. When compared with the conversion period, in planting technology, and at the stage of certification, riceduck farming and rice-fish farming technologies used for pest control and weeding have now been replaced by biological herbicide to ensure the quality of organic rice. At the same time, the use of technology in the $\mathrm{T}$ farm has further enhanced the cultivation and processes of managing organic rice farms. In terms of production costs, the farmers surveyed indicate that there is little difference between organic paddy rice and conventional paddy rice and between conversion period and certification of organic paddy rice. The main gap is in the per unit of yield. As such, the issue of how to improve the yield of organic paddy rice has to be tackled. In terms of earnings, $T$ farm through function based on the contract that pays higher income to organic paddy rice farmers. Though this can increase a farmer`s enthusiasm for organic farming, in the long term, it is not conducive for the sustainable development of organic paddy rice farming. Therefore, emphasis has to be given to basic methods of fertilization, rice transplanting, and labour employment using scientific reasoning and technology to achieve the purpose of reducing cost and maximizing profits for improvement of the management of $\mathrm{T}$ farms in future organic paddy rice development.

\section{Selected References}

Bao Zongshun, "Comparison of Technology and Economy between Conventional and Organic paddy rice," Journal of Agrotechnical Economics, Vol.6-10, 2000, pp 40-44. (In Chinese)

Chen Ruibin, Xi, Yunguan, Xu Xin, Wnhg Hai, Yang Jianpin, Fan Weimei, "Comparison of Economic Benefit between Organic Rice and Convention Rice Production". GuiZhou Agricultural Science, Vol. 37-6, 2009, pp 96-98. (In Chinese)

Jin, Liandeng, "A Study on the Present Situation and Development Countermeasures of Organic Rice production in China", China Rice, Vol. 3-1, 2007, pp 1-4. 
Lin Xuegui, "The Development and Problems of Organic Certification System in China”, Journal of the Rural Issues, No.66, 2012, pp 20-29. (In Japanese)

Shen Wanbin, Mao Zhiwei, Su Hua, Bao Guozhang, "Planning for the Rational Exploitation and Utilization of Groundwater Resources in Baicheng City", Arid Zone Reasearch. Vol.21-3, 2004, pp 215-219. (In Chinese) 
